\title{
A Statistical-Based Framework for Predicting Supplier's Behavior to Quality Requirement Changes in Supply Chain
}

\author{
Ekaterina Koromyslova ${ }^{1}$, Jerry Visser ${ }^{2}$ \\ ${ }^{1}$ Department of Construction and Operations Management, South Dakota State University, Brookings, SD, USA \\ ${ }^{2}$ Quality Department, Daktronics, Brookings, SD, USA \\ Email: Ekaterina.Koromyslova@sdstate.edu
}

Received 21 November 2015; accepted 12 December 2015; published 15 December 2015

Copyright (C) 2015 by authors and Scientific Research Publishing Inc.

This work is licensed under the Creative Commons Attribution International License (CC BY). http://creativecommons.org/licenses/by/4.0/

c) (i) Open Access

\begin{abstract}
Companies-manufacturers have to deal with demand and supply uncertainties. They need to adjust to changing customer needs and to be able to pass new quality requirements through the supply chain. Even if suppliers' performance is satisfactory in stable environment, they can behave differently in dynamic situation. Some suppliers can fail to meet new quality requirements or even quit the supply chain. Underestimation of suppliers' motivation can lead to loss of sales, customers, and can face the situation of need of new supplier search. The goal of this paper is to highlight an importance of consideration of informal factors in relationships with supply chain and to discuss a methodology of approach to predict high risk suppliers for changing quality requirements.
\end{abstract}

\section{Keywords}

Supplier's Motivation and Behavior, Informal Relationship Factors, High-Risk Suppliers, Quality Requirements

\section{Introduction}

Providing high quality products for customers is vital in modern competitive market. A manufacturer is a frontline company for quality of a final product which is responsible for customer satisfaction and for communicating quality requirements to all tiers of suppliers. Successful transmission of quality requirements through a supply chain is impossible without effective supplier relationship management.

Quality is the most popular traditional factor in supplier evaluation and it takes a leading role among all other factors. Delivery and Cost are the next most important factors placed after Quality [1]. As manufacturers try to 
bring costs down, there are pressures in other tiers of the supply chain to aggressively reduce material input costs. This leads to challenges to maintain material properties and conformance to specifications and regulatory reporting. Some low level suppliers may be excluded because they do not have the infrastructure to administer these documentation expectations. Customers then have to determine if they continue to work with these lower cost suppliers by either mentoring or ignoring the non-compliance. These decisions typically will turn from the rigid compliance to informal criteria.

In other industries, such as construction or large equipment installations, locally sourced products are politically favorable. Large construction projects may need to include regional suppliers to garner public enthusiasm for tax supported facilities. Thus, the informal network to achieve the request for proposals begins.

Although many companies acknowledge high influence of informal factors on customer-supplier relationship, their role, in comparison to traditional factors of supplier selection and assessment, is underestimated and requires more attention of researchers and practitioners [2]-[7].

Last decade, supplier's motivation and behavior have been admitted as an important part of supplier relationship management and supply chain performance [8]-[11]. Analysis of contribution of the informal factors to supplier's motivation provides better understanding of supplier's behavior under changing conditions, particularly, under quality requirements change. Opportunity to determine the likelihood of undesirable actions of suppliers will allow manufacturers to make better decision on strategic relationships and resources investment decisions for suppliers development.

The objectives of this paper are to highlight an importance of consideration of informal factors in relationships with suppliers and to discuss a methodology of approach to predict high risk suppliers for changing quality requirements.

\section{Background}

\subsection{Role of Informal Factors in Supplier's Motivation and Behavior in Supply Chain}

In this research, informal factor can be defined as a factor which influences manufacturer-supplier relationship, but is out of limits of formal business relationships of a supply chain partners, for instance, personal relationship, familiarity with a company, history of relationships, etc. Traditional factors are the factors which acknowledged by company management for formal supplier evaluation, selection, and decision making, such as quality, delivery, price, and others. Review of previous studies confirmed interest of researchers to this topic and its importance. Thus, Forker [2] determined critical quality management factors and tested relationship of these factors, actual quality performance, and relative efficiency of suppliers. The list of factors investigated by the author includes traditional factors utilized by supply chain managers and procurement managers, such as quality programs and attitudes, quality information systems, production training and workforce policies.

Contemporary research in this area paid more attention to informal factors. For instance, ten years later Wuyts [8] introduced concept of extra-role supplier behavior, when suppliers exceed expectations and go beyond the formal role, determined in a contract, due to influence of both traditional and informal factors, such as switching cost, partner qualification, cooperative atmosphere, and reputation. Using statistical analysis, the author demonstrated significance of informal factors and direct positive relationship of the all factors and profitability of partners. External factors (environment uncertainty, technology uncertainty, power asymmetry, demand uncertainty) influence on operational performance, developing trust and long-term relationship of supply chain partners were investigated by researchers [3] [12]. 48 failure factors for enterprise resource planning system were defined and investigated by Yuan-Du, Ching-Chow, Wen-Tsann, \& Wei-Cheng [13]. The authors developed risk assessment and prediction methodology introducing the performance index calculation and performance evaluation matrix. Jayaram, Xu, \& Nicolae [14] investigated supplier coordination factor on quality and flexibility in context of firm size and clockspeed. Therefore, variety of factors and their influence on different outcomes have been studied last two decades.

Many of the most recent research indicate a shift of attention to informal factors and investigate an importance of personal relationship in business communication of supply chain partners (Gligor \& Autry, 2012). In global supply chain context, supplier culture factor becomes one of important informal factors in supplier relationship management [4] [15]. Barnes, Leonidou, Siu, \& Leonidou [7] supported the concept of cultural differentiation within social exchange theory framework. The authors highlighted that for Chinese companies the informal factors such as friendship and family relationship play leading role in supplier selection, relationship 
building, and trust to partners. Personal communication, credibility, and affection positively influence interfirm relationship quality and financial performance in Chinese organizations.

Thus, importance of different kinds of factors and their influence on supply chain outcomes is evident. To summarize the review of previous studies, following classification of factors, shown on Figure 1, is offered for further methodology development.

\subsection{Classification of Factors in Supplier Relationship Management}

Various combinations of factors presented on Figure 1 have been studied, although some of informal factors were not included in the studies, for instance, history of relationships, location of supplier, and status of a company-manufacturer. Some of factors were considered only from one stand point. Thus, "Location" was mentioned as demographic factor, but not as informal factor in terms of familiarity with local companies, and not as "culture" in terms of national features of foreign partners.

Following outcomes were considered in previous research: communication, quality of relationships, flexibility, operational performance, long-term relationship, trust, and extra-role behavior. Nevertheless, the role of informal factors on quality outcomes under changing requirements has not been studied yet. This research will contribute to the theory of supplier relationship management by determination the factors' influence and their interaction influence on suppliers motivation and predicting their behavior on quality requirements change.

\section{Methodology for Developing a Predictive Model of Supplier Behavior to Quality Requirements Change}

Previous research investigated influence of informal factors on suppliers' long-term relationship, extra-role behavior, and operational performance, and positive relationship of informal factors and the listed outcomes were proven. Nevertheless, in case of quality requirements change the impact of informal factors on supplier's behavior and quality outcomes can be different. For instance, such informal factors as personal relationship (friendship, family relationship) can have both positive and negative influence on quality outcomes because of "feeling of impunity" and confidence that a manufacturer will continue relationship with the supplier even in case of quality failure. According to social psychology, an individual behaves differently depending on attitudes of other people and environment conditions. This theory is applicable to organizational behavior and can be implemented to describe interaction of two or more groups of people. Thus, determination of pure influence of informal factors on supplier's behavior cannot reflect true supplier's motivation and as a result to predict desired quality outcomes. Combination of factors and their interrelationship should be considered to understand suppliers' motivation in supply chain relationships and predict their behavior on quality requirements changes.

Following methodology is proposed to develop a model of predicting supplier's behavior. The methodology

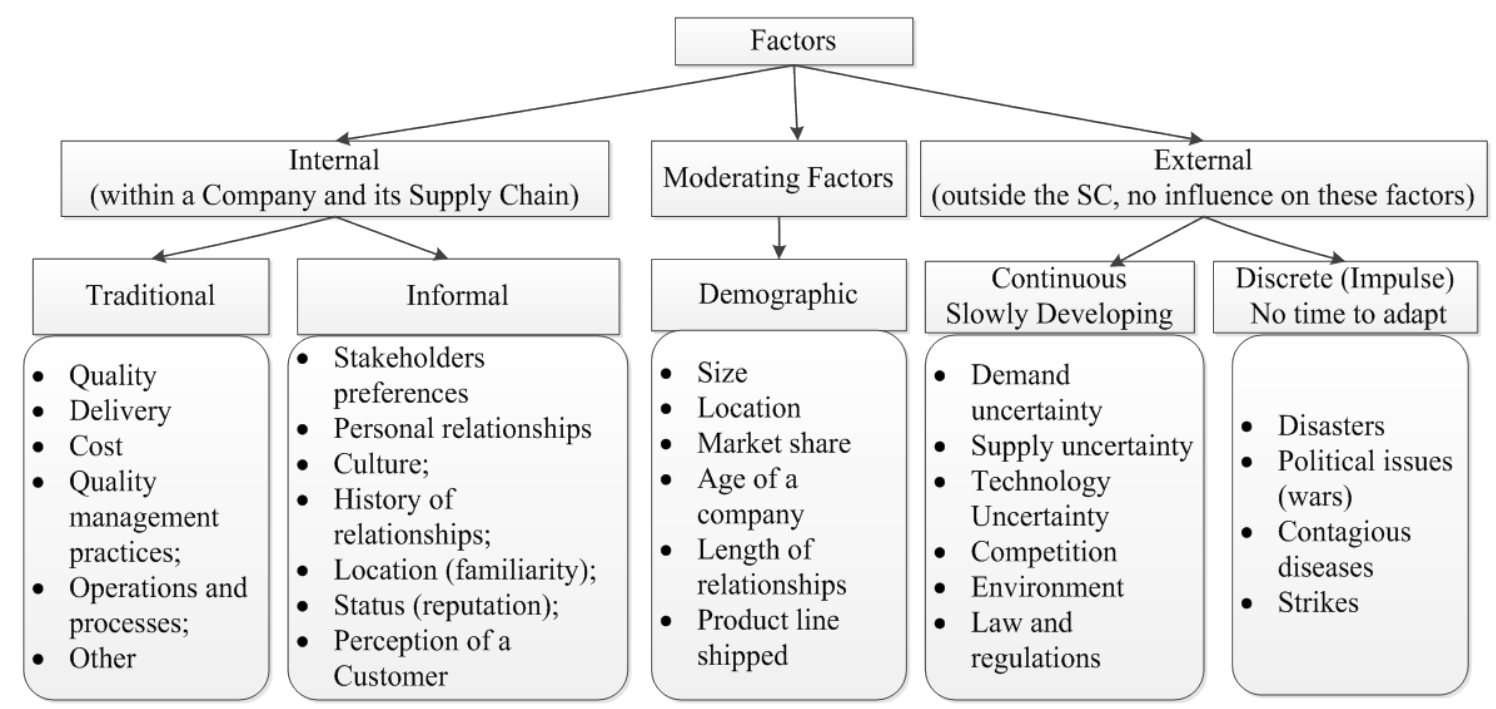

Figure 1. Factors contributing to the supplier relationship management. 
includes several steps for the predicting model development. At the first step, two sets of data are required for statistical analysis, determination of significant factors, their interaction, and sensitivity analysis. First set of data should be collected from companies-manufacturers via semi-structured interview and complimentary questionnaires based on both perceptional measures [14] and actual metrics of supplier's quality performance [2] in stable environment and in dynamic settings of quality requirements changes. The interview and questionnaires will focus on suppliers of items with high supply risk: "strategic" and "bottleneck" items according to Kraljic matrix. The second set of data should be collected from the "strategic" and "bottleneck" suppliers, evaluated by companies-manufacturers, via Likert scale questionnaires [2] with three group of questions: demographic information, internal factors (traditional and informal), and external factors. Both data sets will be combined in statistical model.

\subsection{Questionnaire Structure}

There are proposed groups of questions for supplier's questionnaire in Table 1.

A manufacturer's questionnaire includes demographic factors (manufacturer's information), role (degree of influence) of internal and external factors on building relationship with suppliers, and actual quality measures of "strategic" and "bottleneck" suppliers:

- Conformance to specifications;

- Product reliability— “the probability of product failing within a specified time period” [2, p. 244];

- Product durability— “the amount of use a product offers a consumer before the product deteriorates” [2, p. 244];

- Quality of shipment;

- Percent of change of metric values after quality requirements change.

\subsection{Theoretical Framework of Statistical Model Development and Sensitivity Analysis}

Statistical analysis of manufacturers and suppliers responses will determine significance of traditional and informal factors on supplier's motivation, and their interaction with demographic and external factors will allow comprehensive determination of supplier's motivation in supply chain. Sensitivity analysis of the statistical model will support prediction of supplier's behavior on quality requirements change. The model structure is shown on Figure 2.

Informal and traditional factors are independent variables, demographic and external factors are moderating factors [14], and supplier's motivation is dependent variable. Combination of independent and moderating variables result in supplier's behavior on quality requirements change. Sensitivity analysis allows determination of variables values limits to move suppliers into higher or lower motivation category.

The next step is supply risk assessment based on suppliers' motivation output. Monte Carlo simulation can be applied to determine probability of meeting requirements for each supplier's category. Moreover, external factors in the model are uncontrollable. Using these factors as unknown input for the model, Monte Carlo simulation

Table 1. Supplier questionnaire structure.

\begin{tabular}{|c|c|c|c|}
\hline \multirow{2}{*}{ Demographic factors } & \multicolumn{2}{|c|}{ Internal factors } & \multirow{2}{*}{ External factors } \\
\hline & Traditional & Informal & \\
\hline $\begin{array}{l}\text { - A firm size (number of } \\
\text { employees, annual sales } \\
\text { volume, market share); } \\
\text { - Location (country, } \\
\text { region, city); } \\
\text { - Age of a firm; } \\
\text { - Length of relationship } \\
\text { with a supply chain } \\
\text { partner; } \\
\text { - Product line shipped }\end{array}$ & $\begin{array}{l}\text { - } \text { Compliance with quality } \\
\text { - } \quad \text { } \text { Dequirements; } \\
\text { - } \quad \text { Corrective and preventive action } \\
\text { - } \text { Qystems; } \\
\text { Quality management program } \\
\text { - } \quad \text { DQM, six sigma); } \\
\text { (ISO certification) Inspection and } \\
\text { - } \quad \text { Prontrol; } \\
\text { - Coordination } \\
\text { - Shipment quality (package, lead } \\
\text { time) }\end{array}$ & $\begin{array}{l}\text { - } \quad \text { “Voice” of company } \\
\text { stakeholders; } \\
\text { - } \quad \text { Individual’s job network; } \\
\text { - } \quad \text { Personal relationship } \\
\text { (friendship) } \\
\text { - } \quad \text { Personal relationship } \\
\text { (family); } \\
\text { - } \quad \text { History of relationship of } \\
\text { - SC partners; } \\
\text { - Location (familiarity, } \\
\text { - closeness); } \\
\text { - Status (reputation) }\end{array}$ & $\begin{array}{l}\text { - } \text { Competitors; } \\
\text { - Shared resources } \\
\text { dependency; } \\
\text { - } \text { Degree of task } \\
\text { dependency; } \\
\text { - } \text { Technology change } \\
\text { uncertainty; } \\
\text { - Environment uncertainty } \\
\text { (currency exchange rate, } \\
\text { laws and regulations, } \\
\text { politics) }\end{array}$ \\
\hline
\end{tabular}




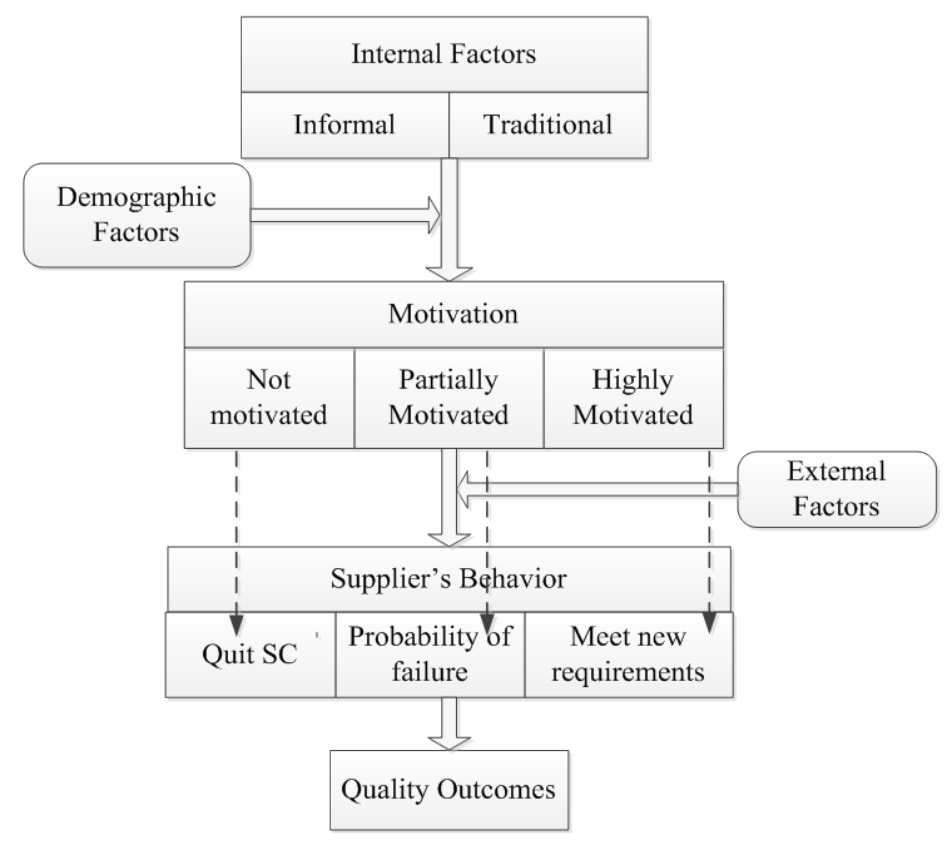

Figure 2. Prediction model structure.

can support decision about long-term partnership and supplier development investments for highly motivated suppliers, and create risk mitigation plan for suppliers with high probability of failure.

\section{Conclusion and Future Research}

Review of previous studies on supplier relationship management in a supply chain supports a need for the current research and proves an importance of the topic. Quality was defined as number one traditional factor in supplier selection and evaluation methodology. Changing nature of market and picky customers enforce manufacturers to be prepared to quality requirements change in the short timeframe, and, therefore, to efficiently pass the new quality requirements over the supply chain.

In this paper broad spectrum of different factors was classified; most important factors for motivation analysis were offered, and role of informal factors in supplier relationship management was emphasized.

Methodology of developing a predictive model of supplier's behavior on quality requirements change was proposed in the paper. Application of motivation theory and social psychology contributed to development of theoretical framework of the behavior prediction model, sensitivity analysis and Monte Carlo simulation implication will allow researchers to make behavior prediction in dynamic settings from strategic standpoint. Understanding the influence of informal factors on suppliers' behavior strengthens supply risk assessment based on supplier's motivation.

Better precision of the model output is expected by utilizing social network analysis for predicting supplier's behavior [16]. A supply chain is basically a network of companies with dependencies on each other's performance. So, to better predict behavior of the tier-1 supplier, it is important to analyze the supplier relationship and dependencies on the suppliers of the next tiers of a supply chain and estimate a "team" effect [17].

The next stage of the research is data collection and application of the created theoretical framework for predicting supplier's behavior on quality requirements change. Sensitivity analysis, Monte Carlo simulation, and social network analysis are further steps to development of the comprehensive and unified model for predicting supplier's behavior.

\section{References}

[1] Ho, W., Xu, X. and Dey, P.K. (2010) Multi-Criteria Decision Making Approaches for Supplier Evaluation and Selection: A Literature Review. European Journal of Operational Research, 202, 16-24.

http://dx.doi.org/10.1016/j.ejor.2009.05.009 
[2] Forker, L. (1997) Factors Affecting Supplier Quality Performance. Journal of Operations Management, 15, $243-269$. http://dx.doi.org/10.1016/S0272-6963(97)00001-6

[3] Ryu, S., Park, J.E. and Min, S. (2007) Factors of Determining Long-Term Orientation in Interfirm Relationships. Journal of Business Research, 60, 1225-1233. http://dx.doi.org/10.1016/j.jbusres.2006.09.031

[4] Cannon, J.P., Doney, P.M., Mullen, M.R. and Petersen, K.J. (2010) Building Long-Term Orientation in Buyer-Supplier Relationships: The Moderating Role of Culture. Journal of Operations Management, 28, 506-521. http://dx.doi.org/10.1016/j.jom.2010.02.002

[5] Gligor, D.M. and Autry, C.W. (2012) The Role of Personal Relationships in Facilitating Supply Chain Communications: A Qualitative Study. Journal of Supply Chain Management, 48, 24-43. http://dx.doi.org/10.1111/j.1745-493X.2011.03240.x

[6] Hartmann, J. and Moeller, S. (2014) Chain Liability in Multitier Supply Chains? Responsibility Attributions for Unsustainable Supplier Behavior. Journal of Operations Management, 32, 281-294. http://dx.doi.org/10.1016/j.jom.2014.01.005

[7] Barnes, B.R., Leonidou, L.C., Siu, N.M. and Leonidou, C.N. (2015) Interpersonal Factors as Drivers of Quality and Performance in Western-Hong Kong Interorganizational Business Relationships. Journal of International Marketing, 23, 23-49. http://dx.doi.org/10.1509/jim.14.0008

[8] Wuyts, S. (2007) Extra-Role Behavior in Buyer-Supplier Relationships. International Journal of Research in Marketing, 24, 301-311. http://dx.doi.org/10.1016/j.ijresmar.2007.05.002

[9] Riedel, R., Neumann, N., Franke, M. and Muller, E. (2010) The Behavior of Suppliers in Supplier-Customer Relationships. In: Vallespir, B. and Alix, T., Eds., Advances in Production Management Systems. New Challenges, New Approaches, Springer, 338 pages. http://dx.doi.org/10.1007/978-3-642-16358-6 33

[10] Romano, P. and Formentini, M. (2012) Designing and Implementing Open Book Accounting in Buyer-Supplier Dyads: A Framework for Supplier Selection and Motivation. International Journal of Production Economics, 137, 68-83. http://dx.doi.org/10.1016/j.ijpe.2012.01.013

[11] Bertrand, O., Lumineau, F. and Fedorova, E. (2014) The Supportive Factors of Firms' Collusive Behavior: Empirical Evidence from Cartels in the European Union. Organization Studies, 35, 881-908. http://dx.doi.org/10.1177/0170840613515471

[12] Chen, I.J. and Paulraj, A. (2004) Towards a Theory of Supply Chain Management: The Constructs and Measurements. Journal of Operations Management, 22, 119. http://dx.doi.org/10.1016/j.jom.2003.12.007

[13] Hsiao, Y.-D., Yang, C.-C., Lin, W.-T. and Lee, W.-C. (2007) A Study on Key Failure Factors for Introducing Enterprise Resource Planning. Human Systems Management, 26, 139-152.

[14] Jayaram, J., Xu, K. and Nicolae, M. (2011) The Direct and Contingency Effects of Supplier Coordination and Customer Coordination on Quality and Flexibility Performance. International Journal of Production Research, 49, 59-85. http://dx.doi.org/10.1080/00207543.2010.508935

[15] Karim, M., Smith, A., Halgamuge, S. and Islam, M. (2008) A Comparative Study of Manufacturing Practices and Performance Variables. International Journal of Production Economics, 112, 841-859. http://dx.doi.org/10.1016/j.ijpe.2007.07.005

[16] Grady, C.A., He, X. and Peeta, S. (2015) Integrating Social Network Analysis with Analytic Network Process for International Development Project Selection. Expert Systems with Applications, 42, 5128-5138. http://dx.doi.org/10.1016/j.eswa.2015.02.039

[17] Crespo, P.T. and Antunes, C. (2015) Predicting Teamwork Results from Social Network Analysis. Expert Systems, 32, 312-325. http://dx.doi.org/10.1111/exsy.12038 